\title{
Fine-scale plant defense variability increases top-down control of an herbivore
}

\author{
Ryan Paul ${ }^{1}$, Ian Pearse ${ }^{2}$, and Paul Ode ${ }^{3}$ \\ ${ }^{1}$ USDA Agricultural Research Service \\ ${ }^{2}$ US Geological Survey \\ ${ }^{3}$ Colorado State University
}

September 9, 2020

\begin{abstract}
Herbivore populations are regulated by plant defenses and natural enemies. While plant defense can suppress herbivore populations, these defenses adversely affect natural enemies thereby releasing herbivores from top-down control. Over their lifespans, herbivores and their natural enemies may experience substantial variation in plant defense. Defense variability can suppress the growth of herbivores, but the impacts of defense variability on natural enemies and top-down control of herbivores are unknown. We independently manipulated the mean and variation of a plant toxin experienced by individual Trichoplusia ni caterpillars and its parasitoid Copidosoma floridanum. Increases in the mean toxin concentration, but not its variance, experienced by individual T. ni and C. floridanum decreased the fitness of C. floridanum, whereas both mean and variance impacted $T$. $n i$ fitness. Thus, increased defense variability for individual herbivores suppressed herbivore fitness with no perceptible cost to top-down control. However, impacts of variability depend heavily on scale of variability.
\end{abstract}

\section{Hosted file}

Main body_Paul, Pearse, Ode_Defense Variability Parasitoids_Ecol letters.pdf available at https://authorea.com/users/357530/articles/480038-fine-scale-plant-defense-variabilityincreases-top-down-control-of-an-herbivore 
SUPPLEMENTAL TABLES AND FIGURES

Table S1: Diet Recipe. Ingredient amounts are for each diet and are listed used in order of

addition. All ingredients were mixed with a Waring industrial blender. Xanthotoxin was

added for experimental diets but not colony rearing.

$\frac{\text { Ingredient }}{\text { Soy Flour }}$

Soy Flour

Casein

Torula Yeast

Alfalfa meal

Ascorbic Acid

Sorbic Acid

Methyl Paraben

Tetracycline

Source

Bio-Serv

Bio-Serv

Bio-Serv

$\begin{array}{ll}37.5 \mathrm{~g} & \text { Bio-Serv } \\ 25 \mathrm{~g} & \text { Bio-Serv }\end{array}$

$31.25 \mathrm{~g} \quad$ Bio-Serv

Bio-Serv

Bio-Serv

Bio-Serv

$\begin{array}{ll}3 \mathrm{~g} & \text { Bio-Serv } \\ 1.5 \mathrm{~g} & \text { Bio-Serv } \\ 2.5 \mathrm{~g} & \text { Sigma-Ald }\end{array}$

Xanthotoxin

$2.5 \mathrm{~g}$

$62.5 \mathrm{mg}$

Sigma-Aldrich

$\begin{array}{ll}\text { Xanthotoxin } & 0,0.5,1,1.5, \text { or } 2 \mathrm{~g} \\ \text { Pinto Beans + Water (cooked) } & 62.5 \mathrm{~g}+250 \mathrm{~mL}\end{array}$

7.4\% Formalin

Raw Linseed Oil $\quad 6.75 \mathrm{~mL}$

Sigma-Aldrich

Agar (heated with water)

Mollinckrodt (Formaldehyde)

Agar (heated

$5 \mathrm{~g}$

Sonyside

MoorAgar 